\title{
Determinants for hospitalization in " low-risk" community acquired pneumonia
}

\author{
Zakari Y Aliyu*1, Muktar H Aliyu² and Ken McCormick ${ }^{3}$
}

Address: ${ }^{1}$ Department of Medicine, St Agnes Hospital, Baltimore, MD, 21229, USA, 2School of Public Health, University of Alabama, Birmingham, Alabama, USA and ${ }^{3}$ Department of Information Services, St. Agnes Hospital, Baltimore, MD, USA

Email: Zakari Y Aliyu* - zyaliyu@cs.com; Muktar H Aliyu - mhaliyu@uab.edu; Ken McCormick - kmccormick@stagnes.org

* Corresponding author

Published: 17 June 2003

BMC Infectious Diseases 2003, 3:II
Received: 02 November 2002

Accepted: 17 June 2003

This article is available from: http://www.biomedcentral.com/I47I-2334/3/II

(C) 2003 Aliyu et al; licensee BioMed Central Ltd. This is an Open Access article: verbatim copying and redistribution of this article are permitted in all media for any purpose, provided this notice is preserved along with the article's original URL.

\begin{abstract}
Background: A variable decision in managing community acquired pneumonia (CAP) is the initial site of care; in-patient versus outpatient. These variations persist despite comprehensive practice guidelines. Patients with a Pneumonia Severity Index (PSI) score lower than seventy have low risk for complications and outpatient antibiotic management is recommended in this group. These patients are generally below the age of fifty years, non-nursing home residents, HIV negative and have no major cardiac, hepatic, renal or malignant diseases.
\end{abstract}

Methods: A retrospective analysis of 296 low-risk CAP patients evaluated within a year one period at St. Agnes Hospital, Baltimore, Maryland was undertaken. All patients were assigned a PSI score. $208(70 \%)$ were evaluated and discharged from the emergency department (E.D.) to complete outpatient antibiotic therapy, while $88(30 \%)$ were hospitalized. Patients were substratified into classes I-V according to PSI. A comparison of demographic, clinical, social and financial parameters was made between the E.D. discharged and hospitalized groups.

Results: Statistically significant differences in favor of the hospitalized group were noted for female gender ( $\mathrm{Cl}$ : I.46-5.89, $\mathrm{p}=0.0018)$, African Americans ( $\mathrm{Cl}: 0.3 \mathrm{I}-0.73, \mathrm{p}=0.004)$, insurance coverage $(\mathrm{Cl}: 0.19-0.63, p=0.0034)$, temperature $(\mathrm{Cl}: 0.04-0.09, p=0.000 \mathrm{I})$ and pulse rate $(\mathrm{Cl}: 0.03-0.14, p=$ $0.000 \mathrm{I})$. No statistically significant differences were observed between the two groups for altered mental status, hypotension, tachypnea, laboratory/radiological parameters and social indicators $(p>0.05)$. The average length of stay for in-patients was 3.5 days at about eight time's higher cost than outpatient management. There was no difference in mortality or treatment failures between the two groups. The documentation rate and justifications for hospitalizing low risk CAP patients by admitting physicians was less than optimal.

Conclusions: High fever, tachycardia, female gender, African- American race and medical insurance coverage are determinants for hospitalization among low risk CAP patients in our study. The average length of stay for in-patients was 3.5 days ( 3 to 5 days). The cost of in-patient care was about eight times higher than outpatient management. This study supports the recommendation of using the PSI for E.D evaluation of patients in appropriate social settings. 


\section{Background}

Community-acquired pneumonia (CAP) is the 6th leading cause of death in the USA and the leading cause of death from an infectious disease.[1,2] Approximately 4 million adults are diagnosed annually and mortality averages $14 \%$ in hospitalized cases.[3] From the standpoint of cost and quality of care, a key decision in management is whether to treat patients as outpatients or as inpatients. There is general agreement that a substantial number of inpatients admitted on the basis of conventional criteria might be safely managed as outpatients. An estimated \$4 billion is expended annually on CAP patients with inpatient therapy costing as much as 20 times outpatient antimicrobial therapy.[4] Risks and probable outcomes in patients with community-acquired pneumonia have always been assessed intuitively by clinicians, but are now being intensively and formally studied. Several risk-scoring systems have been developed to assign patients to different risk categories with respect to important outcomes such as mortality or intensive care unit admission. [5] The need for determining hospitalization criteria led to the development of the Pneumonia Severity Index (PSI) by the Pneumonia Outcomes Research Team.[6] The PSI index stratifies patients into five classes with those in class I and II (PSI < 70) representing 'low risk' individuals that can be safely managed at home.

This study uniquely integrates analyses of demographic, social and financial factors in addition to clinical factors in an attempt to evaluate their significance in decisions involving hospital admissions of low-risk CAP patients. This would provide a better understanding to the interaction of physician, patient and health system factors in admitting low-risk CAP patients. In addition, comparing the average cost of hospitalization of low-risk patients with the average cost of outpatient CAP antimicrobial therapy provides a picture of potential financial savings to the health care system.

\section{Methods}

Adult patients age 18-49 years seen with a primary diagnosis of simple community-acquired pneumonia (ICD-9: 486 ) at the Emergency Department (ED), St Agnes Hospital, Baltimore between January $1^{\text {st }} 2000$ and December $31^{\text {st }} 2000$ were identified from the computerized hospital record system $\left(\right.$ Meditech $^{\circledR}$ ). St. Agnes hospital is a community hospital, which serves the ethnically diverse inner city of Baltimore and its environs. Exclusion criteria for this study were: age greater than 50 years, HIV/AIDS, nursing home resident status and patients with major renal failure, hepatic, cardiac and malignant disorders. These categories of patients were excluded because they are likely to fall into the "high-risk" classification for community acquired pneumonia (PSI scores above 70) and more likely to be admitted with other morbidities as the pri- mary diagnosis. Additionally, patients who failed outpatient therapy, those with prior hospitalization within thirty days of the index hospitalization, those readmitted within thirty days with any other condition and those with documented poor oral intake, persistent nausea, vomiting or dehydration were also excluded. Patients who satisfied the inclusion criteria were stratified into PSI classes using the Pneumonia Outcomes Research Team (PORT) criteria. PSI class II patients that were seen and managed as outpatients were then compared using demographic, social, financial, laboratory, clinical, radiological and hospital care variables to hospitalized PSI class II patients.

The variable used as the basis of comparison included demographic characteristics (age, gender and ethnicitywhich have socioeconomic implications); social and economic parameters, (alcoholism/substance abuse, insurance status) and hospital care variables (length of stay, average cost of hospitalization, time and day of presentation to ED). Additionally, clinical indicators considered included altered mental status, respiratory rate, systolic $\mathrm{BP}$, temperature and pulse rate. Laboratory and radiographic findings (arterial blood $\mathrm{pH}$, blood urea nitrogen level, sodium level, hematocrit, partial pressure oxygen/ saturation, and pleural effusion) were also compared between PSI class II patients' admitted and those treated as out patients. Only the initial documented clinical and laboratory/radiological parameters were included in the study. It is important to note the ED and primary care physicians did not use the PSI during the study period. Structured telephone interviews were designed to determine the outcomes of the ED discharged group. Specifically, repeat $\mathrm{ED}$ visits or hospitalizations within thirty days of discharge fromm our ED was determined. Deaths within thirty days of ED discharge possibly due primarily to pneumonia or related to complications of the disease were also assessed.

\section{Statistical analysis}

The principal study objective was determination of statistically significant differences in variables assessed between PSI class II ED discharged patients and those admitted. $\mathrm{SAS}^{\circledast}$ v8.2 was used in all statistical analyses. The raw data was read into SAS ${ }^{\circledast}$ from EXCEL ${ }^{\circledast}$ data sheet. Based on the categorical nature of the data collected, chi square tests using PROC FREQ option were used to determine statistically significant associations between each demographic, clinical and laboratory/radiologic parameter and disposition (ED discharge versus hospitalization). PROC MEANS option was used to determine the mean age in years and mean cost of care for each group of patients. Associations were considered statistically significant where $\mathrm{p}<0.05$ (two-tailed hypothesis). 
Table I: PSI classes of ED discharged and hospitalized patients with community-acquired pneumonia

\begin{tabular}{lll}
\hline Class & Discharged No. (\%) & Hospitalized No. (\%) \\
\hline I & 0 & 0 \\
II & $169(8 I)$ & $67(76)$ \\
III & $36(17)$ & $11(13)$ \\
IV & $3(1)$ & $10(11)$ \\
V & 0 & 0 \\
\hline
\end{tabular}

(Numbers in parenthesis represent percentages)

\section{Results}

A total of 296 patients were evaluated in the emergency department with a diagnosis of simple community acquired pneumonia (ICD-9: 486) during the study period (refer table 1 ). The age range for all patients was 18-49 years; mean 35.6 years. Two hundred and eight patients $(70 \%)$ were discharged from the emergency room while 88 (30\%) were admitted for inpatient management. A breakdown of the ED discharged group by class revealed 169 (81\%) were PSI class II, 36 (17\%) were class III and 3 (1\%) were class IV. In the admitted groups 67 (76\%) were class II, 11 (13\%) were class III and 10 (11\%) class IV. (Table 1) Classes $\mathrm{V}$ and $\mathrm{I}$ had no representation in either the ED discharged or admitted groups.

The demographic, clinical, laboratory and radiological comparison between PSI class II ED discharged and class II admitted is shown in table 2. Patients' ages were similar in the two groups; (mean ages, $39 \pm 5.3$ years and $37 \pm 8.7$ years for ED discharged and hospitalized patients, respectively). In the ED class II discharged group, 66 (39\%) were males and 103 (61\%) females, compared to 12 males $(18 \%)$ and 55 females $(88 \%)$ in the class II hospitalized group $(\mathrm{p}=.0018) .57 \%$ of patients seen on outpatient basis (ED class II discharged) were whites while 69\% of those admitted were African-Amereican $(\mathrm{p}=.0004)$. There were no patients with either tachypnea (RR > 30) or altered mental status in either group but statistically significant differences were seen for 2 clinical parameters (temperature and pulse rate, $\mathrm{p}<.0001$ ). Majority of patients in both ED discharged and admitted groups were covered by private insurance $(\mathrm{p}=.0034)$. The average length of stay for PSI class II patients seen and hospitalized was 3.5 days at an average cost of $\$ 3909 \pm 347.3$. The estimated mean cost of outpatient management was $\$ 476.02 \pm 99.25$. All patients in the admitted group were discharged directly home. There was no short or longterm care placement and there were complications noted. One hundred and eighteen (70\%) of the 169 of the ED discharged groups were successfully reached via telephone for interview. Three $(2.5 \%)$ of the one hundred eighteen patients interviewed in the ED discharge group had a sec- ond ED visit within thirty days with fever, cough and sore throat which may be attributed to failed outpatient therapy. Interestingly, these patients visited different emergency departments. Five patients (4\%) visited the primary care doctors within one week for failure to tolerate the initial antibiotics prescribed and persistent malaise. None required re-hospitalization. Seven patients (6\%) felt they should have been hospitalized for better care and more intense investigations.

\section{Discussion}

Management of community acquired pneumonia has been progressively complicated by several factors: expanding spectrum of causative organisms, rising prevalence of antibiotic resistance, increasing population of patients with advancing age and with comorbidities and the interest in reducing the number of unnecessary admissions. The initial site of care decision is perhaps the single most important clinical decision made by physicians during the entire course of illness for patients with CAP. It has a direct bearing on the intensity of laboratory testing, microbiologic evaluation, antibiotic therapy and costs of treating this illness. The estimated average cost of inpatient care for CAP is $\$ 7500$ compared with $\$ 150-\$ 350$ for outpatient care. [2]

The pneumonia severity index shows a direct correlation between risk class and risk of death and has been validated as a guide for decisions regarding hospitalization. Age is a major component of the PSI. The age of the patient is added to other parameters used in the index. Patients above the age of fifty were excluded in the study. These patients are more likely to have chronic comorbid conditions, which places them in higher risk CAP group, in contrast to the target CAP population of our study. Several factors that the rule does not take into account may greatly influence the decision to admit a patient, the most important being factors related to the patient such as poor social support, inability to maintain oral intake and history of substance abuse. The admission decision may also be influenced by the availability of outpatient support 
Table 2: Result of statistical analysis comparing demographic, clinical and laboratory/ radiological variables (PSI class II ED discharged and class II hospitalized)

\begin{tabular}{|c|c|c|c|c|}
\hline Variables & Discharged $N=169$ No. (\%) & Hospitalized N = 67 No. (\%) & OR $[95 \% \mathrm{Cl}]$ & $\mathrm{p}$-value \\
\hline \multicolumn{5}{|l|}{ Demographics } \\
\hline Age in years (mean $\pm s d$ ) & $39 \pm 5.29$ & $37 \pm 8.76$ & - & - \\
\hline \multicolumn{5}{|l|}{ Gender } \\
\hline Male & $66(39)$ & $12(18)$ & $2.94[1.46-5.89]$ & 0.0018 \\
\hline Female & $103(6 I)$ & $55(82)$ & & \\
\hline \multicolumn{5}{|l|}{ Race } \\
\hline African-American & $68(40)$ & $46(69)$ & $0.06[0.04-0.09]$ & 0.0004 \\
\hline Whites & $97(57)$ & $20(30)$ & & \\
\hline Others & $4(3)$ & $1(1)$ & & \\
\hline \multicolumn{5}{|l|}{ Clinical } \\
\hline Change in mental status & - & - & - & - \\
\hline Respiratory Rate $>30$ & - & - & - & - \\
\hline $\mathrm{SBP}<90 \mathrm{mmHg}$ & $13(8)$ & $5(7)$ & $0.97[0.33-2.83]$ & 0.9522 \\
\hline Temp $>105 \mathrm{~F}$ & $2(I)$ & $24(36)$ & $0.02[0.01-0.09]$ & $<0.0001$ \\
\hline Pulse rate $>125$ & $15(9)$ & $39(58)$ & $0.07[0.03-0.14]$ & $<0.0001$ \\
\hline \multicolumn{5}{|l|}{ Laboratory/ Radiological } \\
\hline Arterial $\mathrm{pH}<7.35$ & $\mathrm{II}(7)$ & $8(12)$ & $0.97[0.33-2.83]$ & 0.9522 \\
\hline $\mathrm{BUN}>30 \mathrm{mg} / \mathrm{dL}$ & $20(12)$ & $9(13)$ & $0.87[0.37-2.01]$ & 0.7359 \\
\hline $\mathrm{Na}<130 \mathrm{mmol} / \mathrm{L}$ & $12(7)$ & $8(12)$ & $0.97[0.33-2.83]$ & 0.9522 \\
\hline Glucose $<250 \mathrm{mg} / \mathrm{dL}$ & $17(10)$ & $6(9)$ & $\mathrm{I} .14[0.43-3.02]$ & 0.7965 \\
\hline Hct $<30 \%$ & $23(14)$ & $11(16)$ & $1.25[0.57-2.73]$ & 0.5796 \\
\hline $\mathrm{pO}_{2}<60 \mathrm{mmHg} / \mathrm{O}_{2}$ sat $<90 \%$ & $26(15)$ & $8(12)$ & $0.75[0.32-1.74]$ & 0.4969 \\
\hline \multicolumn{5}{|l|}{ Social factors } \\
\hline Alcohol-related diagnosis & $28(17)$ & $18(27)$ & $1.85[0.94-3.64]$ & 0.0718 \\
\hline Illicit drug use & $23(14)$ & $11(16)$ & $1.25[0.57-2.73]$ & 0.5796 \\
\hline \multicolumn{5}{|l|}{ Time of ED visit } \\
\hline $7 \mathrm{am}-7 \mathrm{pm}$ & $101(60)$ & $39(58)$ & $0.94[0.53-1.67]$ & 0.8265 \\
\hline 7pm-7am & $68(40)$ & $28(42)$ & & \\
\hline \multicolumn{5}{|l|}{ Day of ED visit } \\
\hline Weekdays & $142(86)$ & $55(83)$ & $0.87[0.41-1.84]$ & 0.7183 \\
\hline Weekends & $27(14)$ & $12(17)$ & & \\
\hline \multicolumn{5}{|l|}{ Financial Factors } \\
\hline \multicolumn{5}{|l|}{ Insurance status } \\
\hline Self pay & $63(37 \%)$ & $10(14 \%)$ & $0.38[0.19-0.63]$ & 0.0034 \\
\hline Private insurance & $88(52 \%)$ & $46(71 \%)$ & & \\
\hline Medical assistance & $18(11 \%)$ & $11(15 \%)$ & & \\
\hline \multicolumn{5}{|l|}{ Utilization of services } \\
\hline$\overline{\text { Average length of stay }}$ & $<1$ day & 3.5 days & - & - \\
\hline \multirow[t]{2}{*}{ Cost of care (mean $\pm s d)$} & $\$ 476.02 \pm$ & $\$ 3909.32 \pm$ & - & - \\
\hline & 99.25 & 347.32 & & \\
\hline
\end{tabular}

(Numbers in parenthesis represent percentages)

services (home nursing, home intravenous therapy) and alternative sites for care (subacute care services).

Demographic and social parameters are clearly important considerations in the quality of care delivered to all patients. In this study, statistically significant differences for gender were seen between the class II patients seen in the ED and subsequently discharged and those hospitalized. The odds of a PSI class II male CAP patient being seen and managed on outpatient basis was 2.9 times the odds of a female patient in the same risk class being managed as an outpatient (95\% CI 1.4632-5.8950). (Table 2)
In a study looking at sex differentials in health Verbrugge found that females generally show a higher incidence of acute conditions, more short-term restricted activity, more use of health services and medicines and were more willing than men to seek medical care for perceived symptoms. [7] Women have also been shown to have greater willingness to acknowledge and report illness.[8] Our findings agree with the view that women are more predisposed than men to rate their health poor and therefore more likely to accept hospitalization compared to males especially if there is agreement between the ED physician and their primary care doctor on admissions.[9] Statisti- 
cally significant higher hospitalization was found among PSI class II African-Americans compared to whites (OR $0.5738,95 \%$ CI $0.3214-0.7326$ ). This finding is interesting in view of the disparities believed to exist between blacks and whites in both need and access to health care services. Previous studies have shown that blacks are less likely to receive medical services particularly intensive care than whites. $[10,11]$ So what could be responsible for the statistically significant higher proportion of blacks in the PSI class II hospitalized group? A national phone survey found that blacks were more likely than whites to report that their physician did not inquire sufficiently about their illness, did not tell them how long it would take for prescribed medicine to work, did not explain the seriousness of their illness or injury and did not discuss test or examination findings. [12] In addition, blacks were less likely than whites to be satisfied with the care provided during their most recent hospitalization or ambulatory care visits.[13] One hypothesis may therefore be that physicians subconsciously prefer to err on the side of caution when managing African American low risk CAP patients in view of their lower socioeconomic status, weaker social support systems and their prevailing higher level of dissatisfaction seen with medical services.

Factors such as education and the skills that come from it inevitably restrict the ability of some black patients to gain access to and negotiate effectively for the best medical treatment available (which in this case may not be hospitalization for a PSI class II patient). [14] In addition, Schoenbaum et al have shown that blacks are less likely to demand or receive adequate information about their disease process and more likely to report themselves to be in poor health than whites of the same age group and gender.[15] It has also been speculated that blacks and whites may differ in terms of their treatment preferences but such a difference has not been documented and may merely be a result of the interaction of complex sociocultural and economic factors. [16]

PSI class II patients with medical insurance coverage had a statistically significant higher hospitalization rate than uninsured patients of the same PSI class (OR 0.4685, 95\%CI 0.1923-0.6981). Numerous studies have shown that uninsured persons have greater difficulty accessing inpatient care, fewer procedures, and shorter hospitalizations, and are more likely to receive substandard care for medical injury.[17,18] A study by Jackson that looked at the impact of health insurance status on emergency room services revealed uninsured emergency patients were less likely to be admitted to the hospital than insured emergency patients.[19] Weissman et al in their study compared hospitalized patients and found that after adjusting for diagnosis related group case mix, uninsured patients had, on average, $7 \%$ shorter stays (5.36 vs. 5.79 days) and underwent $7 \%$ fewer procedures (1.16 vs. 1.25$)$ than insured patients, the differences varying with hospital type.[20] Halm et al theorized greater involvement by primary care physicians who are more likely to admit low risk patients could be responsible for the similar differences seen in their study since uninsured patients are often admitted to the service of house staff and frequently have their need for hospitalization reassessed by a senior physician.[21] The decision to hospitalize is not necessarily a commitment to long-term inpatient care but rather a decision that certain patients should be closely observed until it is clear that therapy can be safely continued out of the hospital. Even in institutions with established clinical guidelines for CAP admissions, adherence is highly variable and associated with a variety of patient, system and physician factors. Since criteria for admissions have not been uniformly applied by clinicians, studies have reported wide geographic variation in hospital admission rates for CAP.[22] In the same study by Halm et al 71 of 163 low risk CAP patients were hospitalized despite recommendation for outpatient therapy.[21]. Physicians' reasons for admission were the presence of active comorbidities (55\%), primary care physician's wish for hospitalization $(41 \%)$, the presence of worse pneumonia than the guideline indicated $(36 \%)$, patient preference $(17 \%)$ and inadequate home support (16\%). In some studies physicians have overestimated the risk of death for patients with CAP leading to unnecessary admissions while in other studies they have failed to recognize patients as being severely ill at the time of initial evaluation. $[6,23]$

The result of our study concurs with others in suggesting factors other than clinical (demographic, socioeconomic) frequently influence physicians decisions for hospitalizing low risk CAP patients. [21,22] High fever and tachycardia were the only clinical parameters with statistically significant differences between the two groups. ( $\mathrm{p}<$ $0.0001)$. No significant differences were identified for other clinical parameters included in the PSI (altered mental status, hypotension and tachypnea, $\mathrm{p}>0.05$ ). There were also no significant differences noted for laboratory and radiological parameters (arterial $\mathrm{pH}, \mathrm{BUN}, \mathrm{Na}$, glucose, hematocrit and pulse oximetery/ $A B G$, pleural effusion, $\mathrm{p}>0.05$ ).

Pressure from overcrowding in the ED or bolus admissions (multiple potential admissions at the same time) may influence physician decisions for hospitalizing low risk CAP patients but this factor is not easy to determine retrospectively. Resident physicians in teaching hospitals like St. Agnes Hospital frequently raise objections to hospitalizing low-risk CAP patients especially early in their training. They however soon realize it is almost easier to write admission orders and send patients to appropriate medical floors rather than spending hours arguing with 
attending physicians in the ED only to finally admit the same patients. It is interesting that neither time of initial ED assessment (7am-7pm versus $7 \mathrm{pm}-7 \mathrm{am}$ ) or day of ED evaluation (weekdays versus weekends) were associated with differences in hospitalization rates of low risk CAP patients. No other studies have found time to be a statistically significant variable in predicting hospitalization of low risk CAP patients. (Table 2)

Although Fine and colleagues state that low-risk patients should be considered as candidates for outpatient therapy, there is evidence that a substantial number of patients in the low risk group would still require hospitalization.[6] A study by Roson and colleagues in Spain [24] found that $40 \%$ of admitted CAP patients were low risk out of which approximately half did not have "irrefutable" reasons for admission. Certain studies have also suggested that the use of PSI as the principal variable in making the admissions decision could compromise patient care especially in the economically disadvantaged.[25] This study is limited by its retrospective nature and relatively small sample size. Our study also excluded patients greater than fifty years of age limiting its significance in older populations. There was also poor documentation by physicians on valid reasons for hospitalizing low risk patients such as persistent nausea and vomiting, dehydration, homelessness and failed prior outpatient management. A similar study found that many patients with a low predicted mortality risk were likely admitted for these reasons.[26] There was no mortality recorded in the PSI class II hospitalized group. All the patients in the admitted group were discharged directly home; there were no short or long-term care placements. While the outcomes of all patients discharged from the ED could not be determined, a substantial number of these patients were reached by telephone to ascertain their outcomes. Potential recall bias due to the greater than one year between the index hospitalization and follow-up interviews is possible. The none-blinded structure of the interviews is also likely to contribute information and investigator biases. Even after considering the potential limitations of this study, no "irrefutable" reasons for hospitalizations were identified.

Despite the fact that some patients might have been hospitalized due to mitigating circumstances like poor oral intake and weak support systems (which were inadequately documented in the charts), the average length of stay for hospitalized low risk CAP patients (3.5 days) is hardly justifiable for low-risk patients. This is indicative of overutilization of resources through unjustifiable hospitalizations. No hospitalized patient was transferred to a nursing home or required other forms of placement that might influence the length of hospital stay. Alcohol and substance abuse related diagnoses were also not statistically different between the two groups ( $\mathrm{p}>$ $0.05)$.

All patients were treated with the current empirical standard of care for CAP i.e. combination of a third generation cephalosporin and a macrolide or flouroquinolone as monotherapy with necessary prescription adjustments after bacteriology results where applicable. The average cost of inpatient care was $\$ 3909.00$ compared to $\$ 476.00$ for outpatient care. The latter reflects the cost of ED assessment and cost of oral outpatient antibiotics. These figures depict an eight-fold higher cost of care in the hospitalized group compared to the outpatient group. The cost of inpatient care in this study is much lower than the $\$ 7500$ average cost reported by Niedermann et al and may be because of the differences between our study populations (younger age group without major comorbidities). [2]

\section{Conclusions}

This study demonstrates existing overhospitalization of low risk CAP patients in the community hospital studied. Nearly three-quarters of PSI class II community-acquired pneumonia patients seen during the period covered were admitted without irrefutable reasons contrary to clinical management recommendations. African-American, female and medically insured patients were more likely to be admitted with low risk CAP. Tachycardia and high fever are strong clinical predictors for hospitalizing low risk CAP patients. There is poor documentation by physicians of reasons for hospitalization of low risk CAP patients. The association between demographic, socioeconomic and clinical variables with physicians' admissions decision of low risk CAP patients indicate the need to incorporate such variables in the clinical management guidelines of these patients. The eight-fold higher cost of care seen in hospitalized patients compared to outpatients of the same risk class is indicative of potential cost savings to the health care system with unifying admission criteria. It would also limit the health care human resource crisis notably, nurse to patient ratio and serve as a quality indicator. The findings of this study adds to existing literature in assisting clinicians adjust their admissions criteria and supports the American Thoracic Society (ATS) and Infectious Disease Society of North America (IDSA) recommendations for use of the PSI in initial decision making for CAP patients. However, the role of the PSI might best be as a component in the algorithm along with social and economic considerations. Such considerations must be clearly and adequately documented to justify such admissions. Similar larger prospective multicenter studies are recommended.

\section{Competing Interests}

Partial funding support for this study was provided by the Saint Agnes foundation and the department of internal 
medicine, St. Agnes Hospital, Baltimore, MD 21229. An earlier version of this paper was presented as an oral paper at the American College of Physicians, Maryland area associates twentieth annual meeting, May 2002, Baltimore, MD. It was also presented and received the best overall poster award at the $96^{\text {th }}$ scientific assembly of the Southern Medical Association, November 2002, Washington, DC.

\section{Authors' Contributions}

Dr. Zakari Yusufu Aliyu was responsible for the initial conception of the study, initial design, data collection and analysis and preparing the initial and final draft of the study.

Dr. Muktar Hassan Aliyu was involved in the initial study design and was responsible for statistical analysis, and initial and final draft preparation of the study.

Mr. Ken McCormick was involved in the initial study design, retrieving and organizing data and data analysis.

\section{Acknowledgements}

The authors acknowledge the support of William Valente, MD, Chairman, Department of Internal Medicine and Armando Sardi, MD, Director, Clinical Research Center, St. Agnes Hospital towards the completion of this work. The critique of the study provided by internal medicine residents at St. Agnes hospital, Baltimore, MD and the faculty and graduate students of the Department of Epidemiology and Biostatistics, The George Washington University, Washington DC is greatly appreciated.

\section{References}

I. Garibaldi RA: Epidemiology of community acquired respiratory tract infections in adults: incidence, etiology and impact Am J Med 1985, 78:32S-37S

2. Niederman MS, Mc Combs JI, Unger AN, Kumar A and Popovian R: The cost of treating community acquired pneumonia Clin Ther 1998, 20:820-837.

3. Bartlett JG, Breiman RF, Mandell LA and File TM: Community acquired pneumonia in adults; Guidelines for management Clin Infect Dis 1998:81 I-38.

4. Fine MJ: Risk stratification for patients with community acquired pneumonia Int J Clin Pract Suppl 2000, I I 5: I4- 17.

5. Marrie TJ: Risks and outcomes in community acquired pneumonia Can Respir J 1999, 6(Suppl A):6A-9A.

6. Fine MJ, Auble TE, Yealy DM, Hanusa BH, Weissfeld LA, Singer DE, Coley CM, Marrie TJ and Kapoor WN: A prediction rule to identify low risk patients with community acquired pneumonia $\mathrm{N}$ Eng J Med 1997, 336:243-250.

7. Verbrugge LM: Sex differentials in health Public Health Rep 1982, 97:417-37.

8. Wingard DL: The sex differential in morbidity, mortality, and lifestyle Annu Rev Public Health 1984, 5:433-58.

9. Waldron I: Sex differences in illness incidence, prognosis and mortality: issues and evidence Soc Sci Med 1983, 17:1 107-23.

10. Yergan J, Flood AB, Logerfo JP and Diehr P: Relationship between patient race and the intensity of hospital services Med Care 1987, 25:592-603.

II. Council on Ethical and Judicial Affairs, AMA, Chicago, III: BlackWhite disparities in Health Care JAMA 1990, 263:2344-2346.

12. Blendon RJ, Aiken LH, Freeman HE and Corey CR: Access to medical care for black and white Americans: a matter of continuing concern JAMA 1989, 26I:278-280.

13. Eisenberg JM: Sociologic influences on decision-making by clinicians Ann Intern Med 1979, 90:957-959.
14. Levy DR: White doctors and black patients: influence of race on the doctor-patient relationship Pediatrics 1985, 75:639-643.

15. Schoenbaum $M$ and Waidmann $T$ : Race, socioeconomic status and health: accounting for race differences in health The Journals of Gerontology Series B 1997, 52B(Special issue):6I-73.

16. Perkoff GT and Anderson M: Relationship between demographic characteristics, patient's chief complaint, and medical care destination in an emergency room Med Care 1970, 8:309-323.

17. Bindman $A B$, Grumbach $K$ and Osmond D: Preventable hospitalizations and access to health care JAMA 1995, 274:305-3II.

18. Burstin HR, Lipsitz SR and Brennan TA: Socioeconomic status and risk for substandard medical care JAMA 1992, 268:2383-2387.

19. Jackson $P$ : The impact of health insurance status on emergency room services J Health Soc Policy 200I, I 4:6I-74.

20. Weissman $J$ and Epstein AM: Case mix and resource utilization by uninsured hospital patients in the Boston metropolitan area JAMA 1989, 26I(24):3572-6.

21. Halm EA, Atlas SJ, Borowsky LH, Benzer TI, Metlay JP, Chang YC and Singer DE: Understanding physician adherence with pneumonia practice guideline: effects of patient, system and physician factors Arch Int Med 2000, 160:98-104.

22. Mc Mahon LF, Wolfe RA and Tedeschi PJ: Variation in hospital admissions among small areas; a comparison of Maine and Michigan Med Care 1989, 27:623-631.

23. Neil AM, Martin IR, Weir R, Anderson R, Chereshsky A, Epton MJ, Jackson R, Schoesboe M, Frampton C, Hutton S, Chambers ST and Town GI: Community acquired pneumonia: etiology and usefulness of severity criteria on admission Thorax 1996, 51:10101016.

24. Roson B and Carratal J: Etiology, reasons for hospitalizations, risk classes and outcomes of CAP patients hospitalized on the basis of conventional criteria Clin Inf Dis 200I, 33:I58-I65.

25. Niederman MS, Mandell LA and Anzueto A: Guidelines for the management of adults with CAP; diagnosis, assessment of severity, antimicrobial therapy and prevention Am J Resp Crit Care Med 200I, 163:1730-I754.

26. Marras TK, Gutierrez $C$ and Chan CK: Applying a prediction rule to identify low-risk patients with community-acquired pneumonia Chest 2000, I I 8:1339-1343.

\section{Pre-publication history}

The pre-publication history for this paper can be accessed here:

http://www.biomedcentral.com/1471-2334/3/11/prepub

Publish with Bio Med Central and every scientist can read your work free of charge

"BioMed Central will be the most significant development for disseminating the results of biomedical research in our lifetime. "

Sir Paul Nurse, Cancer Research UK

Your research papers will be:

- available free of charge to the entire biomedical community

- peer reviewed and published immediately upon acceptance

- cited in PubMed and archived on PubMed Central

- yours - you keep the copyright

Submit your manuscript here:

http://www.biomedcentral.com/info/publishing_adv.asp
BioMedcentral 